\title{
Relation between Weight Bearing Ratio in the Standing Posture Immediately after Performing Standing Task and Balance and Functional Ambulation in Stroke Patients
}

\author{
Da-Gyeom Hwang, Joong-Hwi Kim \\ Department of Physical Therapy, Graduate School, Catholic University of Daegu, Gyeongsan, Korea
}

\begin{abstract}
Purpose: The purpose of this study was to provide methods for assessment of functional balance through study of correlation with the weight bearing ratio, functional balance, and functional gait on patients with stroke.

Methods: Thirty-nine patients with stroke participated in this study. The timed up and go test was used to measure balance and the functional ambulation category test to measure functional gait. Weight bearing was measured in the quiet standing posture and weight bearing in the quiet standing posture immediately after performing the standing-task.

Results: Both timed up and go test and functional ambulation category test showed significant correlation with balance in the quiet standing posture immediately after performing the standing task.

Conclusion: Measurement of balance in the quiet standing posture immediately after performing the standing-task was considered a meaningful scale for measurement of both balance function and gait function of patients with stroke.
\end{abstract}

Keywords: Stroke, Balance, Weight bearing ratio

\section{서 론}

뇌졸중으로 인한 편마비 환자의 자세적 특성은 서 있는 자세에서 비 환측으로 체중을 많이 싣는 체중 부하 비대칭과 자세 동요로 인한 균 형 능력의 저하 등으로 특징지어진다. ${ }^{1}$ 이러한 편마비 환자들의 비대 칭적인 하지 체중 부하율 분포는 서기 자세의 유지와 정상적인 운동 패턴의 확립을 방해하고 기능적인 활동을 제한하며, 낙상의 최대 원 인이 된다. ${ }^{2}$ 이러한 이유로 편마비 환자에게서 보행기능, 자세조절, 균 형을 증가시키기 위해 손상측으로 체중이동과 체중지지를 촉진시키 는 활동이 강조되어 왔다. ${ }^{3,4}$

특히 편마비 환자는 감각과 운동감각의 소실로 인하여 일어서기 과정에서 균형을 유지하는 데 어려움을 겪게 되며 마비측으로의 체 중 이동이 감소되어 균형에 어려움을 느끼게 된다. ${ }^{5}$ 균형은 바닥면 안 에 중력 중심을 위치시켜 자세 안정성을 유지하는 능력으로 정적인 균형과 동적인 균형으로 나뉠 수 있는데 정적 균형은 고정된 지면에 흔들림 없이 자세를 유지할수 있는 능력을 의미하고 동적 균형은 움 직이는 지지면에서 혹은 외부 자극이 있을 때, 혹은 능동적으로 움직

Received Sep 15, 2015 Revised Oct 15, 2015

Accepted Oct 19, 2015

Corresponding author Da-Gyeom Hwang

E-mail h0154@hanmail.net
일 때의 균형을 의미한다. ${ }^{6}$ 뇌졸중 환자를 대상으로 하는 균형에 대 한 여러 연구들이 컴퓨터 시스템과 다양한 힘판장비를 통해 이루어 져 왔으며, 본 연구에서도 foot scan (Tech-storm, Seoul, Korea) 장비를 이용하여 정적 선 자세와 일어서기 과제를 통한 정적 선 자세에서 균 형 특성을 분석하였다.

정적 선 자세 균형은 체중을 이동할 수 있는 능력이고 기능적인 움 직임의 필수 조건이고 일어서기나 걷기, 계단오르기 등과 같은 일상 생활의 활동을 위해 중요하다. 또한 앉았다 일어서기 과제를 통한 선 자세 균형은 일어서는 과정에서의 속도와 두 하지의 최대 수직반발 력이 중요한 변수로 작용하며 이는 기능적인 보행능력으로 이어진다 고 할 수 있다. 일상 생활 동작 중 일어 서기는 하루 중 빈번하게 실시 하는 동작으로 질량 중심을 낮은 자세에서 높은 자세로 옮겨가는 동 적인 과정이라 할수 있다. ${ }^{9}$ Park 등 ${ }^{10}$ 은 불안정 지지면에서 일어서기 동작 훈련을 통해 대칭적 체중지지가 증가하여 균형 능력이 향상됨 을 검증하였고 $\mathrm{Hu}$ 등'은 편마비 환자에게 비마비측에 지팡이를 적 용한 후 앉았다 일어서기 훈련을 하였을 때 마비측 슬관절 신전근의 근력 강화와 대칭적인 체중지지 효과가 나타났다고 검증하였다. 
따라서 본 연구는 일어서기를 통한 동작훈련이 대칭적 체중 지지를 유도하여 기능적 균형과 기능적 보행을 향상시켜 정적 및 동적 균형 을 개선시킬 수 있음을 증명한 여러 연구들을 바탕으로 일어서기 과 제 수행을 통해 기능적 균형평가 방법을 제시하는 데 그 목적이 있다.

\section{연구방법}

\section{1. 연구대상}

본 연구는 뇌졸중으로 인한 편마비로 진단을 받고 병원에서 입원 또 는 외래를 통한 치료를 받고 있는 환자들 중에서 앉았다 일어서기가 가능한 환자 39 명을 대상으로 하였다. 대상자 선정 조건은 뇌졸중이 처음 발병하였고 뇌졸중 발병 후 6 개월 이상이 경과한 환자, MMSE-K 에서 24점 이상으로 인지 기능의 장애가 없다고 판명된 자, 하지에 정 형외과적인 질환이 없는 자, 본 연구에 자발적으로 동의하고 참여하 기로 한 자로 하였다. 연구 대상자들의 특성은 다음과 같다(Table 1).

\section{2. 연구방법}

\section{1) 측정도구}

(1) 족저 스캔 시스템(foot scan system)

편마비 환자의 체중 부하율 양상을 측정하기 위해 발판(plate) 형태인 Foot scan system을 사용하였다. Foot scan system (Tech-storm, Seoul, Korea)은 한국표준과학 연구원에서 $98 \%$ 의 신뢰성을 평가받은 장비 로 발바닥의 정적, 동적 압력 분포와 무게균형을 간단하게 측정할 수 있고 비전문가도 쉽게 분석할 수 있도록 구성되어 있다. 또한 압력중 심 이동경로를 볼 수 있으며, 발의 길이, 폭, 보행의 각도 등을 계산 할 수 있다. 센서의 면적은 $384 \mathrm{~mm} \times 384 \mathrm{~mm}$ 로 컴퓨터에 USB로 연결하 여 이미지와 데이터를 볼수 있다. 왼쪽 화면에 환자에 대한 정보를 입 력하고 보행이나 자세 기능을 설정한 후 시작 버튼을 클릭하면 발바 닥에 대한 정보와 무게 균형의 비율이 분석되어 오른쪽 화면에 나타

Table 1. General characteristics of subjects

$(n=39)$

\begin{tabular}{llcc}
\hline Characteristic & & N or M \pm SD & Percent (\%) \\
\hline Sex & Male & 30 & 76.9 \\
\multirow{2}{*}{ Diagnosis } & Female & 9 & 23.1 \\
& Hemorrhage & 20 & 51.3 \\
Affected side & Infarction & 19 & 48.7 \\
& Right & 18 & 46.2 \\
Age & Left & 21 & 53.8 \\
Months after stroke & & $49.4 \pm 10.8$ & \\
Height & & $16.7 \pm 7.0$ & \\
Weight & & $168.3 \pm 8.8$ & \\
\hline
\end{tabular}

$\mathrm{M} \pm \mathrm{SD}:$ Mean \pm standard deviation.
나게 된다. 오른쪽 화면에 나타난 각각의 아이콘을 클릭하면 각 기능 에 대한 정보를 주 영상에서 볼수 있다.

(2) 일어서서 걷기 검사(timed up \& go test, TUG)

동적 균형을 위한 평가 척도로써 TUG 검사를 사용하였다. TUG 검 사는 기능적 운동성을 측정할 수 있는 방법으로 팔걸이가 있는 의자 에 앉은 자세에서 일어나 $3 \mathrm{~m}$ 를 왕복하여 돌아와 다시 앉는 시간을 측정하는 것이며, 단위는 $\sec$ 로 표시된다. 이 검사는 평상시 신발과 보 행 보조 도구를 사용할 수 있으나 다른 사람의 도움을 받지 않고 측 정하며, $20 \mathrm{sec}$ 이상이면 기능적인 운동 손상이 있음을 의미한다. BBS 와 아주 높은 상관관계를 가지고 있으며, 균형과 보행속도 및 기능적 동작들을 평가하는데 타당도가 높은 것으로 나타났다. ${ }^{12}$ 검사자 간 및 검사-재검사 신뢰도는 0.99 이다. 측정 방법 상기의 내용대로 3 회 반복하여 측정된 자료의 평균값을 분석하였다. TUG는 20 초 이상이 면 낮은 균형기능으로 분류하고, 20 초 미만이면 높은 균형기능을 가 진 것으로 분류하였다.

\section{(3) 기능적 보행지수(functional ambulation category, FAC)}

뇌졸중 환자의 기능적인 보행 수준을 평가하기 위하여 $\mathrm{FAC}$ 를 사용 하였다. $\mathrm{FAC}$ 검사는 지지 유무와 정도에 따라 보행을 6 단계로 구분하 고 있으며 보행이 가능한 경우 $=0$ 점, 1 인의 지속적인 지지가 필요한 경우 $=1$ 점, 1 인의 간헐적인 도움이 필요한 경우 $=2$ 점, 신체적 접속 없 이 지시 또는 관찰이 필요한 경우 $=3$ 점, 독립적으로 평지는 걸을 수 있으나 계단이나 불안정한 평지를 걸을 때에 도움이 필요한 경우 $=4$ 점, 독립적으로 보행이 가능한 경우 $=5$ 점으로 구성되어 있다. 다발성 경화증 환자에서 측정자 간 신뢰도는 0.98 이었으며 뇌졸중 환자의 재 검사 간 신뢰도는 0.99 였다. ${ }^{13}$ 보행기능에 따른 체중 부하율을 측정하 기 위해 FAC 점수가 0-2점 사이는 낮은 보행 기능을 가진 것으로 분 류하고 3-5점 사이는 높은 보행기능을 가진 것으로 분류하였다.

\section{2) 연구절차}

대상자의 선정 기준에 적합한 대상자를 선정하여 모집하고 환자들 에 대한 기초 평가를 시행하였으며, 모든 대상자들에게 실험 절차에 대하여 자세히 설명하였다. 먼저 모든 대상자들에 대해서 기능적 균 형 척도인 TUG와 FAC 평가를 하여 자료를 얻었다. 검사자는 정적 선 자세에서 체중 부하의 측정을 위해 연구 대상자들의 보조기와 신발 등을 벗긴 후, 대상자들이 발판(foot plate)에 올라서도록 지시하고 움 직임이 안정되고 나면 시작 버튼을 클릭하였다. 대상자들의 주위 집 중을 위해 조용하고 좁은 공간에서 실시하였으며 전방 $5 \mathrm{~m}$ 앞에 직 경 $5 \mathrm{~cm}$ 의 표시에 시선을 고정하게 하여 편안하게 서 있도록 하였다. 대상자들의 의도적인 움직임을 제한하기 위해 체중 분포를 측정하 
는지의 여부는 알려주지 않고 측정하였다. 또한 검사자는 일어서기 과제 후 정적 선 자세 체중 분포의 측정을 위해 대상자에게 높이 50 $\mathrm{cm}$ 의 등받이가 있는 의자에 허리를 세우고 앉게 하였다가 일어서기 동작을 지시하고, 일어선 직후의 체중 분포를 측정하였다. 시작 자세 인 앉아 있는 동작에서 발바닥이 바닥에서 떨어지지 않도록 구두 지 시를 하였고 앉은 자세가 안정되고 나면 발을 이동하지 않고 바로 일 어서도록 하였다. 한 대상자가 이 두 가지 과제를 동시에 수행하지 않 았으며 무작위 순서로 수행하였다. 환측에 대한 체중 부하율을 얻기 위해 비환측 체중분포에 대한 환측의 체중분포의 비율로 계산하여 자료를 얻었다. 환측에 대한 체중 부하율이 증가한다는 것은 대칭성 이 증가한다는 의미로 받아들여질 수 있으며, 환측과 비환측이 대칭 이 될수록 1 에 가까워지는 값을 갖는다는 특성을 가진다.

환측체중 부하율(weight bearing ratio on affected side, WBR-AS)

= 환측체중분포 $(\%) /$ 비환측체중분포 $(\%)$

\section{3) 자료분석}

연구 대상자의 일반적인 특성은 기술 통계량을 이용해 분석하였다. 정적 선 자세 균형 $(\mathrm{QSB})$ 과 일어서기 과제 후 정적 선 자세 균형 $(\mathrm{QS}-$ BAST)에 대한 환측과 비환측 체중분포 비교와 환측 체중 부하율 (weight bearing ratio on affected side, WBR-AS)의 비교는 대응표본 t-검 정(paired t-test)을 이용하였다. 각각의 TUG와 FAC기능에 따른 QSB 와 QSRAST에서 환측 체중 부하율에 대한 비교는 독립표본 $\mathrm{t}$-검정 (Independent t-test)을 이용하였고 이들의 상관관계는 스피어만 상관 계수(Spearman correlation coefficient)를 이용하여 분석하였다. 분석 은 SPSS 18.0 version을 사용하였고 통계학적 유의 수준 $\alpha=0.05$ 로 정 하였다.

\section{결 과}

\section{1. 정적 선 자세 균형(QSB)과 일어서기 과제 직후 정적 선 자세 균형(QSBAST)에서 환측 체중 부하율 비교}

정적 선 자세 균형(QSB)의 환측체중 부하율(WBR-AS)은 $0.76 \pm 0.18$ 이

Table 2. A comparison of weight bearing ratio on affected side between quiet standing posture balance and quiet standing posture balance after performing standing-task

$(n=39)$

\begin{tabular}{lccc}
\hline Group & Value & $\mathrm{t}$ & $\mathrm{p}$ \\
\hline QSB (WBR-AS) & $0.76 \pm 0.18$ & 4.811 & $<0.001$ \\
QSBAST (WBR-AS) & $0.68 \pm 0.20$ & & \\
\hline
\end{tabular}

Values are mean \pm standard deviation.

QSB: Quiet standing posture balance, QSBAST: Quiet standing posture balance after performing standing-task, WBR-AS: Weight bearing ratio on affected side.
고 일어서기 과제 직후 정적 선 자세 균형(QSBAST)의 환측 체중 부하 율은 $0.68 \pm 0.20$ 으로 차이 값은 0.08 로 QSBAST의 환측 체중 부하율 이 QSB의 환측 체중 부하율에 비해 통계학적으로 유의한 차이를 내 며 낮은 값을 보였다 $(\mathrm{p}<0.01)$ (Table 2).

\section{TUG 기능에 따른 정적 선 자세 균형(QSB)과 일어서기 과제 직후 정적 선 자세 균형(QSBAST)에서 환측 체중 부하율 비교}

정적 선 자세 균형(QSB)에서 낮은 TUG 점수를 나타낸 대상자들은 환측 체중 부하율이 $0.70 \pm 0.20$ 이고, 높은 TUG 점수를 나타낸 대상 자들은 $0.83 \pm 0.19$ 로 통계학적으로 유의한 차이를 보였다 $(\mathrm{p}<0.05)$. 일 어서기 과제 직후 정적 선 자세 균형(QSBAST)에서는 낮은 TUG 점수 를 나타낸 대상자들은 환측 체중 부하율이 $0.60 \pm 0.20$ 이고, 높은 TUG 점수를 나타낸 대상자들은 $0.77 \pm 0.17$ 로 통계학적으로 유의한 차이를 보였다 $(\mathrm{p}<0.01)$ (Table 3$)$.

\section{3. $\mathrm{FAC}$ 기능에 따른 정적 선 자세 균형(QSB)과 일어서기 과제 직후 정적 선 자세 균형(QSBAST)에서의 환측 체중 부하율 비교}

정적 선 자세 균형 $(\mathrm{QSB})$ 에서 낮은 $\mathrm{FAC}$ 점수를 나타낸 대상자들은 환 측 체중 부하율이 $0.67 \pm 0.18$ 이고, 높은 $\mathrm{FAC}$ 점수를 나타낸 대상자들 은 $0.85 \pm 0.12$ 로 통계학적으로 유의한 차이를 보였다 $(\mathrm{p}<0.01)$. 일어서 기 과제 후 정적 선 자세 균형(QSBAST)에서는 낮은 FAC 점수를 나타 낸 대상자들은 환측 체중 부하율이 $0.56 \pm 0.16$ 이고, 높은 $\mathrm{FAC}$ 점수를 나타낸 대상자들은 $0.78 \pm 0.18$ 로 통계학적으로 유의한 차이를 보였다 $(\mathrm{p}<0.01)($ Table 4$)$.

\section{TUG와 FAC와 정적 선 자세 균형(QSB)과 일어서기 과제 직후 정적 선 자세 균형(QSBAST)에서 환측 체중 부하율의 상관성 비교}

정적 선 자세 균형(QSB)와 일어서기 과제 직후 정적 선 자세 균형(QS$\mathrm{BAST}$ )의 환측 체중 부하율과 TUG 및 FAC와의 상관관계를 비교한

Table 3. A comparison of weight bearing ratio on affected side between quiet standing posture balance and quiet standing posture balance after performing standing-task according to TUG function

\begin{tabular}{lcccc}
\hline Group & TUG function & Value & $\mathrm{t}$ & $\mathrm{p}$ \\
\hline QSB (WBR-AR) & Low & $0.70 \pm 0.20$ & $-2.39^{*}$ & 0.022 \\
QSB (WBR-AR) & High & $0.83 \pm 0.19$ & & \\
QSBAST (WBR-AR) & Low & $0.60 \pm 0.20$ & $-2.90^{+}$ & 0.006 \\
QSBAST (WBR-AR) & High & $0.77 \pm 0.17$ & & \\
\hline
\end{tabular}

Values are mean \pm standard deviation.

QSB: Quiet standing posture balance, QSBAST: Quiet standing posture balance after performing standing-task, WBR-AS: Weight bearing ratio on affected side, Low TUG function: Above 20 sec score, High TUG function: Under 20 sec score. ${ }^{*} p<0.05,{ }^{+} p<0.01$. 
Table 4. A comparison of weight bearing ratio on affected side between quiet standing posture balance and quiet standing posture balance after performing standing-task according to FAC function

\begin{tabular}{lcccc}
\hline Group & FAC function & Value & $\mathrm{t}$ & $\mathrm{p}$ \\
\hline QSB (WBR-AS) & Low & $0.67 \pm 0.18$ & -3.65 & 0.001 \\
QSB (WBR-AS) & High & $0.85 \pm 0.12$ & & \\
QSBAST (WBR-AS) & Low & $0.56 \pm 0.16$ & -4.12 & $<0.001$ \\
QSBAST (WBR-AS) & High & $0.78 \pm 0.18$ & & \\
\hline
\end{tabular}

Values are mean \pm standard deviation.

QSB: Quiet standing posture balance, QSBAST: Quiet standing posture balance after performing standing-task, WBR-AS: Weight bearing ratio on affected side (Affected side/non-affected side), Low FAC function: 0-2 point, High FAC function: 3-5 point.

결과 TUG는 정적 선 자세 균형과 $r=-0.53(\mathrm{p}=0.005)$, 일어서기 과제 직 후 정적 선 자세 균형과는 $\mathrm{r}=-0.50(\mathrm{p}=0.008)$ 의 값을 보였으며 $\mathrm{FAC}$ 는 정적 선 자세 균형과 $\mathrm{r}=0.57(\mathrm{p}=0.002)$, 일어서기 과제 직후 정적 선 자 세 균형과 $\mathrm{r}=0.62(\mathrm{p}=0.001)$ 의 값으로 TUG와 FAC 모두에서 일어서기 과제 직후 정적 선 자세 균형과 더 높은 상관관계를 보였다(Table 5).

\section{고 찰}

본 연구에서는 일어서기 과제 직후 정적 선 자세에서의 균형 측정 방 법을 통하여 기능적인 균형과 동적 균형 더 나아가 기능적 보행과의 상관관계에 대해 연구하고자 하였다. 균형과 체중 부하의 능력과는 매우 높은 상관관계를 가지며 균형 능력의 회복은 뇌졸중 환자의 주 된 재활 과정 목표가 된다. 특히 뇌졸중 이후에 발생하는 운동적, 감 각적, 인지적인 문제들로 인해 선 자세 균형을 제어하는 데 있어 상당 한 어려움에 직면하게 되며 균형 수행과 보행 수행 시 마비측으로 체 중을 옮기는 능력이 감소한다. ${ }^{14}$

본 연구에서 39 명 환자를 대상으로 정적 선 자세와 일어서기 과제 직후 정적 선 자세에서의 체중분포를 측정한 결과 두 자세 모두에서 환측의 체중분포가 비환측 체중분포에 비해 통계적으로 유의하게 낮은 값을 보였는데, 이는 다른 선행 연구에서 비환측의 체중분포가 23-44\%를 나타냈다는 연구 결과들과 유사하다. ${ }^{15}$ 정적 선 자세에서 체중분포도를 측정하는 방법은 일반적인 균형 측정 방법이라고 할 수 있고 일어서기 과제를 통한 체중분포도를 측정하는 방법은 동적 인 균형을 측정하는 방법이라고 할 수 있는데, 이는 일반적으로 일어 서기 동작은 좁아진 지지면에서 안정적으로 압력 중심을 이동시켜 야 하며 능력과 환경에 따라 전략을 수정하는 능력이 필요로 하기 때 문이라고 할 수 있다. ${ }^{16}$

본 연구에서 일어서기 과제 직후 정적 선 자세의 환측 체중 부하율 (환측 체중분포/비환측 체중분포)이 정적 선 자세에서의 환측 체중 부하율에 비해 통계적으로 유의한 차이를 내며 낮은 값을 보였는데,
Table 5. Correlation between weight bearing ratios on affected side of quiet standing posture balance and quiet standing posture balance after performing standing-task, TUG and FAC

\begin{tabular}{lcc}
\hline & QSB & QSBAST \\
\hline TUG & $-0.53(p=0.005)$ & $-0.50(p=0.008)$ \\
FAC & $0.57(p=0.002)$ & $0.62(p=0.001)$ \\
\hline
\end{tabular}

QSB: Quiet standing posture balance, QSBAST: Quiet standing posture balance after performing standing-task, TUG: Timed Up \& Go test, FAC: Functional Ambulation Category.

이는 Camenron 등 ${ }^{17}$ 이 일어서기 동작 동안 운동에너지의 감소와 속 도의 증가로 비환측의 체중 부하율이 큰 체중 부하의 비대칭을 나타 낸다고 하였으며 본 연구 결과와 일치점을 보이고 있다. 일상에서 반 복적으로 일어나는 일어서기 동작에 대한 건측과 환측의 체중 부하 율에 대한 분석은 보행과 같은 기능적 움직임의 비대칭성을 예측하 는 데 중요한 정보가 될 수 있을 것이다. 본 연구에서는 정적 선 자세 에서의 균형과 일어서기 과제 직후 정적 선 자세 균형이 기능적인 균 형과 동적 균형 더 나아가 기능적인 보행과의 상관성을 알아보기 위 해 균형의 평가 척도인 TUG와 보행의 평가 척도인 $\mathrm{FAC}$ 를 기능에 따 라 분류하였다. 그 결과 TUG와 균형과의 관계에서는 TUG 기능이 높 을수록 환측에 대한 체중 부하율이 높음을 보였다. Geiger 등18은 균 형 능력 장비를 이용하여 환측에 대한 체중 부하 훈련을 실시한 결과 TUG 점수가 향상되었다고 하였고, Son 등 19 은 환측의 발목에 대한 관 절 가동화 기법을 적용하여 체중이동 훈련을 하여 $10 \mathrm{~m}$ 보행속도를 측정한 결과 실험 전 평균 $0.49 \mathrm{~m} / \mathrm{s}$ 에서 실험 후 $0.55 \mathrm{~m} / \mathrm{s}$ 로 속도가 유 의하게 증가되었다고 하였다. 이는 임상적으로 보행 속도는 일상생활 을 수행할 수 있는 독립적 보행 능력과 기능 회복 수준을 가늠할 수 있는 척도로 사용되는데, ${ }^{20}$ 환측에 대한 체중 부하율을 높이는 것이 보행 속도의 향상과 연관이 있다는 것을 의미한다. 또한 $\mathrm{FAC}$ 와 균형 과의 관계에서는 FAC 기능이 높을수록 환측에 대한 체중 부하율이 높음을 보였다. 기능적 보행이란 다양한 주위 환경에서 최대한 독립 적으로 보행을 할 수 있는 개인의 능력을 의미하며 뇌졸중 환자의 절 반 이상은 기능적 보행 능력의 회복을 위해 지속적인 재활을 필요로 한다. ${ }^{21} \mathrm{Hesse}$ 등 22 은 부분적인 체중 지지가 가능한 트레드밀 훈련을 129 일 동안 실시한 결과 기능적 보행 지수가 2.2점 향상되었음을 보 고하였고, $\mathrm{Kim}$ 등 $20^{2}$ 뇌졸중 환자의 기능적인 균형과 보행과의 상관 관계를 연구하여 보행 대칭성과 기능적인 보행 능력이 보행 능력 회 복에 의미 있는 기준이 된다는 것을 보고하였다. 이와 같은 결과는 환측에 대한 체중 부하율을 높이는 것이 기능적 보행 능력의 향상과 연관성이 있음을 의미한다.

이어서 TUG와 FAC와 정적 선 자세 균형과 일어서기 과제 직후 정 적 선 자세 균형과의 상관성을 알아본 결과 FAC와 TUG 모두에서 일 어서기 과제 직후 정적 선 자세 균형과 더 높은 상관관계 값을 보였다. 
이는 정적 균형을 측정하는 데 있어 단순히 정적 선 자세 균형을 측 정 하는 것보다 일어서기 과제 직후 정적 선 자세 균형을 측정하는 것 이 기능적인 균형과 기능적인 보행 능력을 반영할 수 있다는 것을 보 여준다. 이는 일어서기 동작이 충분한 관절의 회전력과 좁아진 지지 면에 안정적으로 압력 중심을 이동시키는 능력과 환경에 따라 전략 을 수정하는 능력이 요구되는 동작이고 ${ }^{16}$, 엉덩이를 떼는 시기는 등 근육과 엉덩 관절 신근을 이용하여 좁은 지지면으로 압력 중심을 이 동하여 굽힘 모멘트를 조절하는 동작으로 고도의 균형 능력이 요구 되는 동작이므로 ${ }^{23}$ 이와 같은 결과가 나왔을 것이라고 사료된다.

본 연구의 제한점은 일어서기 과정에서의 발의 압력 중심(central of pressure)의 변화와 체중심 변화와 같은 생역학적인 변수들은 고려하 지 못하였다는 점이다. 결론적으로, 일어서기 과제 직후 정적 선 자세 균형을 측정하는 것은 정적인 균형뿐만이 아니라 기능적인 균형과 보행을 반영할 수 있는 방법이므로 뇌졸중 환자의 균형을 측정하는 데 있어 정적인 선 자세에서의 균형을 측정하기보다 일어서기 과제 직후 정적 선 자세 균형을 측정하는 것이 더 의미있는 평가 방법이라 고 생각되며 이는 임상 현장에서 뇌졸중 환자의 기능적 평가를 위한 새로운 지표로 활용될 수 있을 것이라고 생각된다.

\section{REFERENCES}

1. Lee JS, Nam KW, Kim KY et al. Effect of weight bearing exercise on weight bearing and balance for patient with chronic stroke. J Kor Phys Ther. 2012;24(4):253-61.

2. Kim JH. A study on the correlation between static, dynamic standing balance symmetric and walking function in stroke. J Kor Phys Ther. 2012;24(2):73-81.

3. Kim SH, Choi JD. The effect of gait training of progressive increasing in body weight support and gait speed on stroke patient. J Kor Phys Ther. 2013;25(5):252-9.

4. Kim JH. The effect of whole body vibration exercise on balance and lower extremity muscle activity in stroke patient. J Kor Phys Ther. 2013; 25(5):266-72.

5. Yang DJ, Park SK, Kang JI. Effect of changes in postural alighnmnet on foot pressure and balance of patient with stroke. J Kor Phys Ther. 2014; 26(4):226-33.

6. Ragnarsdóttir M. The concept of balance. Physiotherapy. 1996; 82(6):368-75.

7. Eng JJ, Chu K. Reliability and comparison of weight-bearing ability dur- ing standing tasks for individuals with chronic stroke. Arch Phys Med Rehabil. 2002;83(8):1138.

8. Chou SW, Wong AM, Leong CP et al. Postural control during sit-to stand and gait in stroke patients. Am J Phys Med Rehabil. 2003;82(1):42-7.

9. Hughes MA, Schenkman ML. Chair rise strategy in the functionally impaired elderly. Journal of rehabilitation research and development. 1996;33(4):409.

10. Park J, Woo YK, Park SY. Effects of sit to stand training unstable surface on balance in subject with stroke. Phys Ther Kor. 2013;20(3):1-8.

11. Hu PT, Lin KH, Lu TW et al. Effect of a cane on sit-to-stand transfer in subjects with hemiparesis. Am J Phys Med Rehabil. 2013;92(3):191-202.

12. Podsiadlo D, Richardson S. The timed" up \& go": A test of basic functional mobility for frail elderly persons. J Am Geriatr Soc. 1991;39(2): 142.

13. Holden MK, Gill KM, Magliozzi MR et al. Clinical gait assessment in the neurologically impaired reliability and meaningfulness. Phys Ther. 1984; 64(1):35-40.

14. Kim JH, Kim CS. Effects of virtual reality program on standing balance in chronic stroke patients. J Kor Phys Ther. 2005;17(3): 351-67.

15. Yu E, Abe M, Masani $\mathrm{K}$ et al. Evaluation of postural control in quiet standing using center of mass acceleration: Comparison among the young, the elderly, and people with stroke. Arch Phys Med Rehabil. 2008;89(6):1133-9.

16. Prudente C, Rodrigues-de-Paula F, Faria CD. Lower limb muscle activation during the sit-to-stand task in subjects who have had a stroke. Am J Phys Med Rehabil. 2013;92(8):666-75.

17. Cameron D, Bohannon R, Garrett G et al. Physical impairments related to kinetic energy during sit-to-stand and curb-climbing following stroke. Clin Biomech. 2003;18(4):332-40.

18. Geiger RA, Allen JB, O'Keefe J et al. Balance and mobility following stroke: Effects of physical therapy interventions with and without biofeedback/forceplate training. Phys Ther. 2001;81(4):995-1005.

19. Son HY, Choi JD. The effect of weight shift training with joint mobilization on balance and gait velocity of hemiplegic patients. Physical Therapy Korea. 2012;19(1):1-9.

20. Kim CM, Eng JJ. The relationship of lower-extremity muscle torque to locomotor performance in people with stroke. Phys Ther. 2003;83(1):49-57.

21. Liaw LJ, Hsieh CL, Lo SK et al. Psychometric properties of the modified emory functional ambulation profile in stroke patients. Clin Rehabil. 2006;20(5):429-37.

22. Hesse S, Bertelt C, Schaffrin A et al. Restoration of gait in nonambulatory hemiparetic patients by treadmill training with partial body-weight support. Arch Phys Med Rehabil. 1994;75(10):1087-93.

23. Ng SS, Cheung SY, Lai LS et al. Association of seat height and arm position on the five times sit-to-stand test times of stroke survivors. BioMed research international. 2013;2013. 